\title{
Seasonal peak electricity demand characteristics: Japan case study
}

\author{
Yusri Syam Akil ${ }^{1,2,}$, Hajime Miyauchi ${ }^{1}$ \\ ${ }^{1}$ Dept. of Frontier Technology for Energy and Devices, Kumamoto University, Kumamoto, Japan \\ ${ }^{2}$ Dept. of Electrical Engineering, Hasanuddin University, Makassar, Indonesia
}

\section{Email address:}

yusuri@st.cs.kumamoto-u.ac.jp(Y. S. Akil),miyauchi@cs.kumamoto-u.ac.jp(H. Miyauchi)

\section{To cite this article:}

Yusri Syam Akil, Hajime Miyauchi. Seasonal Peak Electricity Demand Characteristics: Japan Case Study. International Journal of Energy and Power Engineering. Vol. 2, No. 3, 2013, pp. 136-142. doi: 10.11648/j.jjepe.20130203.18

\begin{abstract}
Because of the need to keep balancing between electricity supply and demand continuously, a demand analysis is necessary as it can provide essential information to manage operation of a power system. This study presents a seasonal peak demand characteristics investigation for commercial area in Japan by developing hourly demand regression models for each season. Meteorological parameters and existing holidays are considered as demand drivers. Many standard statistical tests are applied to the models. From results, typical forms of link between commercial demand and key drivers at peak hours (daytime and evening) in each season can be revealed through the models. Knowing more detail characteristic of a demand particularly during high load hours can help utilities to maintain expected optimal operation of power systems and service to consumers all the time.
\end{abstract}

Keywords: Peak Demand, Characteristics, Season, Commercial Area, Regression Analysis

\section{Introduction}

Generally, electricity load demand served by a power system is not constant in one day and it has maximum values at a certain hour which is known as peak period. Among service period to consumers, utilities concern mainly at peak hours since demand is high. Under high demand, a certain system can run in an extreme condition. Furthermore, risks such as frequency oscillation, severe voltage violation [1], and load shedding can take place in the system. Thus, it is necessary to keep balance between supply and demand at all times to reduce such risks. However, electricity demands can be influenced by meteorological parameters. From this viewpoint, knowing more information about (peak) demands and role of the related driver variables is valuable for utilities. It may help them in managing existing power plants to meet volume of demand more effective. As demand drivers may unique in one place [2], determining key drivers and their effects become a challenging task when conducting a demand analysis such as characteristic investigation. In [3-6], the significance effect of meteorological parameters as main variables on the studied electricity demand is confirmed.

Previous studies on peak load demand in different places can be found in [1,7-9]. Reference [1] reported the implementation of strategies to reduce peak demand in Desert Southwest region of the US because of cooling load. Reference [7] conducted study about effect of daylighting on peak demand in Hong Kong. Reference [8] analyzed residential area in Brazil for electricity conservation and reduction of peak load. In [9], the authors analyzed utilization of renewable energy in India to reduce existing peak load.

In this study, we focus to investigate seasonal peak demand characteristics of commercial area in Japan. The investigation involves daytime and evening peaks for four different seasons in Japan. Seasonal demand models [10] are used as a basis to compose hourly peak demand regression models. From this, direct link between peak load and key variables in each season is recognized. Typical relationship of seasonal demands at peak time to the variables is shown and analyzed further. The presented results may give more insight in identifying characteristics between peak demands and driver variables. This research may give contribution to the operation of power systems. It can become a basis in decision making relating to seasonal planning needed to keep balancing between supply and peak demand.

This paper is organized as follows; data input and seasonal variations for commercial demand are described in Section 2. Next, Section 3 presents seasonal peak demand 
and proposed models. Section 4 presents results of regression models and typical characteristics of peak demands. The conclusions are presented in Section 5.

\section{Data and Demand Variation for Each Season}

\subsection{Data Description}

In this paper, peak demand characteristics analysis is done for commercial area in one typical city in Japan. Historical data offered by a utility are normalized hourly demand data from June 2007 to November 2009. To explain demand, parameters of meteorological and holidays for same period are considered. The meteorological data from public website of Japan Meteorological Agency [11] are temperature $T\left({ }^{\circ} \mathrm{C}\right)$ and relative humidity $R H D(\%)$. Category for holidays covers Saturday, Sunday, national holidays, and two non-national holidays i.e. New Year event (2 to 3 January) and Obon Festival (13 to 16 August). Working activities in Japan are small within these non-national holidays.

\subsection{Variation of Commercial Demand in Each Season}

In Japan, there are four different seasons occurred every year i.e. summer, autumn, winter, and spring. Naturally, summer (June - August) has peak period in July or August. Meanwhile winter (December - February) has peak period in January. Spring (March - May) and autumn (September November) are off-peak periods. Situations of the seasons are unique in each place, and may affect electricity demand.

Fig. 1 shows a sample of daily commercial demand curve in each season and humidity values. They are demands on 3 and 4 August 2008 (summer), 5 and 6 October 2008 (autumn), 6 and 7 January 2008 (winter), and 11 and 12 May 2008 (spring) which represents typical electricity

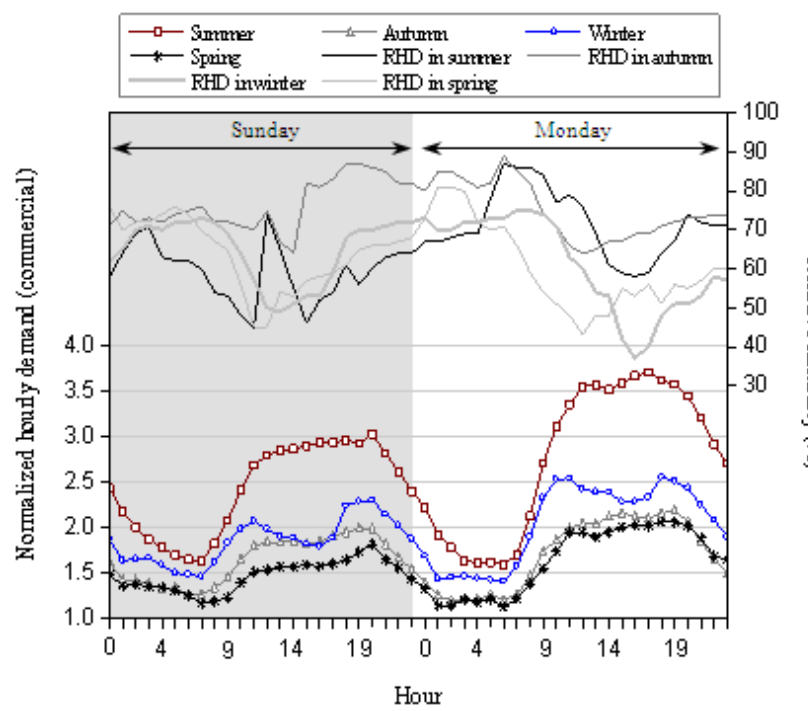

Figure 1. Plots of electricity demand curve and humidity value for each season on the certain day.

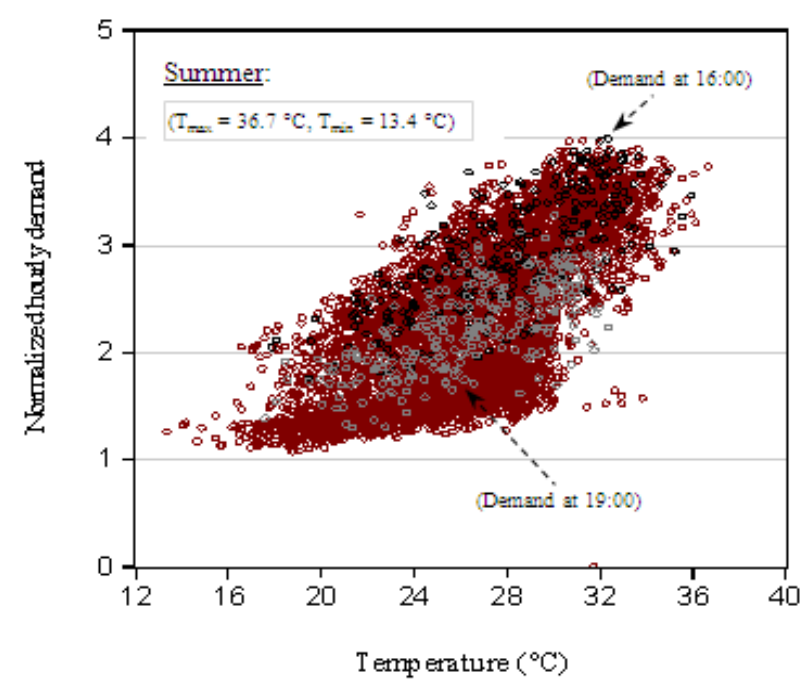

(a)

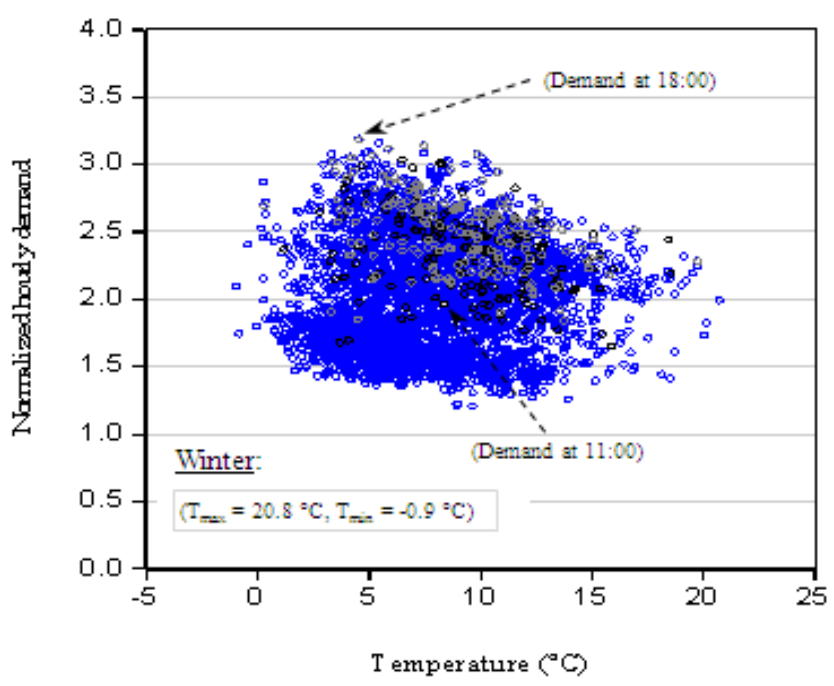

(b)

Figure 2. Seasonal scatter plot of commercial demand versus temperature: (a) summer, (b) winter.

consumption in each season. The electricity demands are a total for two commercial areas. In the figure, electricity demands are higher in non-holidays than in holidays. Demand in summer is highest. Peak demands appear around daytime and evening for all seasons. However, daytime peak demand for winter occurs earlier than other seasons. The influence of severe cold condition in the morning at business places contributes to the situation. Meanwhile Fig. 2 presents variation of relationship between demand and temperature for summer and winter. Basically, it is shown that demand has own characteristics in each season. However, a further investigation is needed to reveal more characteristics. This study is focused on peak demand characteristics. Composing regression models to investigate peak demand characteristics is based on the best seasonal demand model. In the following section, we describe the proposed models. 


\section{Seasonal Peak Demand and Proposed Model}

As a basis in composing and also comparing for peak demand models, demand model for each season [10] is initially constructed. Each seasonal model is referred as all-demand-time (ADT) model. Constructing ADT model is done by selecting proper variables particularly for temperature functions (CDD and HDD) in each season. $C D D$ and $H D D$ are cooling and heating degree days, expressed in (1) and (2) $[3,6,12]$.

$$
\begin{aligned}
& H D D=\max \left(T_{r e f 1}-T, 0\right) \\
& C D D=\max \left(T-T_{r e f 2}, 0\right)
\end{aligned}
$$

In summer and autumn, high temperature is dominant. On the contrary, in winter and spring. However, cold temperature is also occurred in autumn (mainly in November), and opposite situation in spring (mainly in May). Thus, only $C D D$ is used for summer model, and only $H D D$ for winter model. For autumn and spring, both $C D D$ and $H D D$ variables are appropriate used in models. Equation of $A D T$ model for each season is given as follows:

Summer ADT model:

$$
C E C S M=\beta_{0}+\beta_{1} C D D+\beta_{2} R H D+\beta_{3} D H+u_{t}
$$

Autumn ADT model:

$$
C E C A=\beta_{0}+\beta_{1} C D D+\beta_{2} H D D+\beta_{3} R H D+\beta_{4} D H+u_{t}
$$

Winter ADT model:

$$
C E C W=\beta_{0}+\beta_{1} H D D+\beta_{2} R H D+\beta_{3} D H+u_{t}
$$

\section{Spring ADT model:}

$$
C E C S=\beta_{0}+\beta_{1} C D D+\beta_{2} H D D+\beta_{3} R H D+\beta_{4} D H+u_{t}
$$

where $\beta_{0}$ and others $\left(\beta_{1}, \beta_{2}, \beta_{3}\right.$, and $\left.\beta_{4}\right)$ are intercept and regression coefficients, respectively. Meanwhile, $D H$ is the dummy for holidays. This dummy $D H$ has value 1 and 0 for holidays and non-holidays, respectively. To get optimal value for $C D D$ and $H D D$, five reference temperature values $\left(16^{\circ} \mathrm{C}, 17^{\circ} \mathrm{C}, 18^{\circ} \mathrm{C}, 19^{\circ} \mathrm{C}\right.$, and $\left.20^{\circ} \mathrm{C}\right)$ for $T_{\text {refl }}=T_{\text {ref } 2}=T_{\text {ref }}$ are tested in each $A D T$ model. For handling serial correlation, we implement autoregressive in the error term of demand models. This usual method is expressed in (7) [13]. Here, autoregressive order two model is applied in the composed regression models. As options, models without and with autoregressive order one model are computed as well.

$$
u_{t}=\rho_{1} u_{t-1}+\rho_{2} u_{t-2}+\ldots+\rho_{p} u_{t-p}+\varepsilon_{t}
$$

where $u_{t}, \rho_{p}, p$, and $\varepsilon_{t}$ are error term, constants, autoregressive order, and a white noise, respectively. After constructing ADT models, seasonal peak demand hours are determined to compose related peak demand models.

\subsection{Commercial Seasonal Peak Demand}

From demand data, seasonal daytime peak demand (DPD) occurs at 16:00 in summer, at 17:00 in autumn, at 11:00 in winter, and at 17:00 in spring. Meanwhile for evening peak demand (EPD), it occurs at 19:00 in summer, at 19:00 in autumn, at 18:00 in winter, and at 19:00 in spring. Here, peak demand is simply highest value among hourly

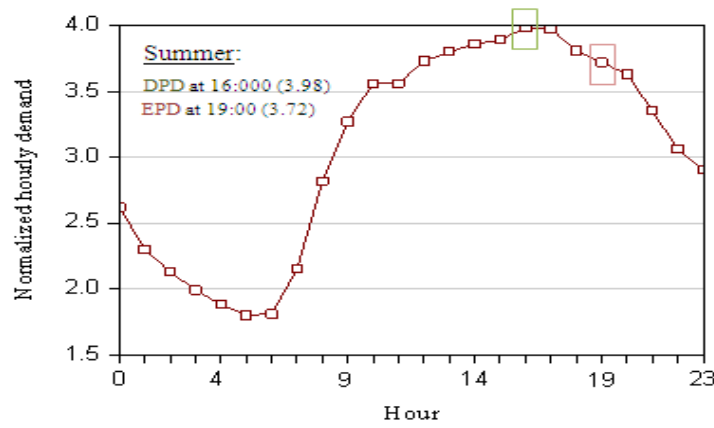

(a)

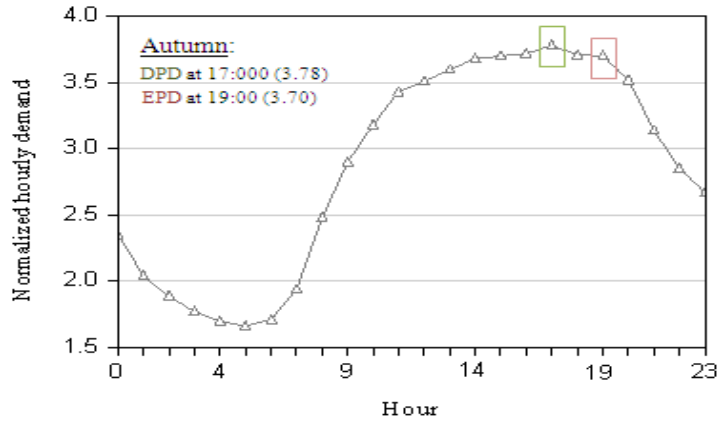

(b)

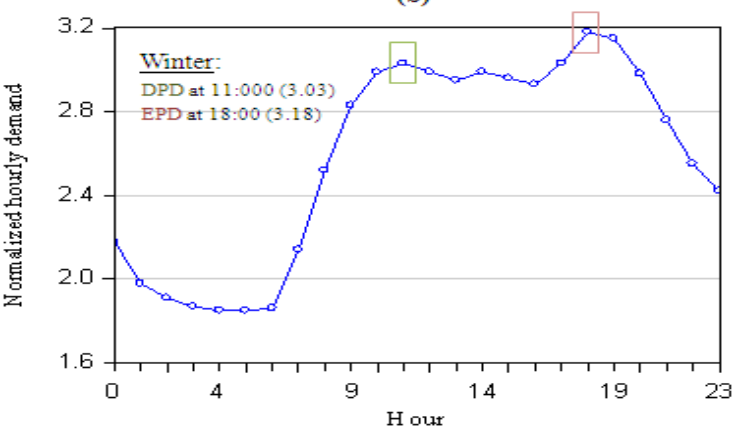

(c)

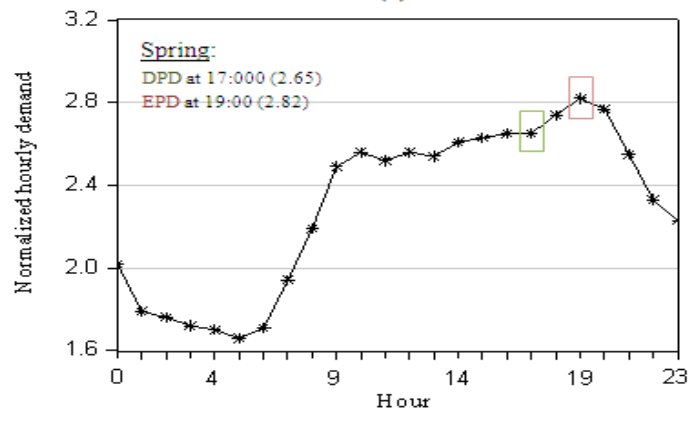

(d)

Figure 3. Plots of the highest seasonal demand value for each hour between June 2007 and November 2009. 
commercial demand (in daytime or evening period) for each season between June 2007 and November 2009. Fig. 3 presents typical highest demand value for each hour in four different seasons. The biggest demand for each period in Fig. 3 is shown in green box for daytime and in red box for evening. Here, daytime and evening periods are based on the daylight condition in each season. In Japan, summer daylight is around 14 hours, from 05.30 to 19.30 . Winter daylight is around 10.5 hours (from 07.00 to 17.30). Meanwhile autumn and spring daylights are roughly 12 hours (from 06.00 to 18.00). In addition, demand variation at peak hours for summer and winter are presented in Fig. 2. Next, demand characteristics at peak time are investigated by composing model for each related hours to identify how far applied variables influence electricity peak load.

\subsection{Hourly Models for Daytime and Evening Peak Demands}

In this part, equations of peak demand models at related hours are presented. As structures of $D P D$ models are based on the $A D T$ models, they are rewritten as follows:

Summer daytime peak demand model:

$$
S M D P D_{16}=\delta_{0}+\delta_{1} C D D+\delta_{2} R H D+\delta_{3} D H+u_{t}
$$

Autumn daytime peak demand model:

$$
A D P D_{17}=\delta_{0}+\delta_{1} C D D+\delta_{2} H D D+\delta_{3} R H D+\delta_{4} D H+u_{t}
$$

Winter daytime peak demand model:

$$
W D P D_{11}=\delta_{0}+\delta_{1} H D D+\delta_{2} R H D+\delta_{3} D H+u_{t}
$$

Spring daytime peak demand model:

$$
S D P D_{17}=\delta_{0}+\delta_{1} C D D+\delta_{2} H D D+\delta_{3} R H D+\delta_{4} D H+u_{t}(
$$

In the above equations, subscript in the name of model, for example 16 in $S M D P D_{16}$, shows the hour when peak summer demand occurred. $\delta_{0}$ is intercept, and $\delta_{1}, \delta_{2}, \delta_{3}$, $\delta_{4}$ are regression coefficients. The remaining variables are the same as in (3) - (6). For EPD models, they are similar to $A D T$ models as well. Next, parameters such as $T_{\text {ref }}$ for $D P D$ and $E P D$ models are based on the related best $A D T$ models.

\section{Results}

Tables 1 and 2 present the best results for ADT models. Best model is based on the lowest value of Akaike Information Criterion $A I C$ and Schwarz Criterion SC tests as in $[3,6]$. Additionally, the highest value for adjusted coefficient of determination $R^{2}$ of model is also assessed. All $A D T$ models are validated well. For tested $T_{r e f}$ values, the results are not significantly different. However under hot seasons, $20{ }^{\circ} \mathrm{C}$ is optimum $T_{\text {ref }}$ for $C E C S M$ and $C E C A$ models. For cold seasons (CECW and CECS models), $16^{\circ} \mathrm{C}$ is best. Obtained $R^{2}$ values are around $81.31 \%$ to $90.11 \%$, with highest value is in summer and lowest one in winter. Durbin-Watson Statistics $D-W$ values are around 2, it represents the absence of autocorrelation. Next, at least one of the explanation variables affects related seasonal demand as Prob. (F-statistics) values are 0 . To handle heteroskedasticity, corrected standard error regression is applied in models [13]. The associated values are listed in Table 1. SE Reg. represents standard error of regression model.

By using $p$-value at significance level of $5 \%$, all variables have significance in each $A D T$ model. $C D D$ and $H D D$ are most significant in models among applied meteorological variables. Meanwhile holidays $D H$ caused commercial electricity demand decreases in each season.

\subsection{Peak Demand Characteristics for Each Season}

Tables 3 to 6 present regression coefficients and statistical tests results for peak demand cases. Parameters models of peak demand such as $T_{\text {ref }}$ value are same with best $A D T$ models. In this study, all model equations are calculated by EViews 6 [14].

For DPD models, values of $R^{2}$ are around $67.20 \%$ to $86.43 \%$ as seen in Table 4. From the $R^{2}$ values, explanation variables can explain $D P D$ at 16:00 highest in summer, and lowest in winter at 11:00. However, all $D P D$ models have fairly good fitness degree. Each peak demand model is validated well. Variables for summer $\left(\mathrm{SMDPD}_{16}\right)$ and spring $\left(\mathrm{SDPD}_{17}\right)$ have significance at $5 \%$ significance level. Meanwhile in other seasons, $H D D$ and $R H D$ have no significance in autumn $\left(\mathrm{ADPD}_{17}\right)$ and in winter model $\left(\mathrm{WDPD}_{11}\right)$, respectively. It is confirmed by $p$-value of their variables are above 0.05 . As autumn is dominated by hot temperature, it may contribute to the non-significance of $H D D$ in $A D P D_{17}$. In the meantime, the low of humidity values in winter months may relate to the non-significance of $R H D$ in $W D P D_{l 1}$. For meteorological variables, regression coefficients for $C D D$ and $H D D$ are larger than $R H D$ in four models. It confirms, $C D D$ and $H D D$ influence much $D P D$ rather than humidity variable (RHD). Under hot seasons (summer and autumn), variable of $C D D$ has highest effect to the maximum loads. RHD shows highest effect in $S M D P D_{16}$ model (0.0072) as values of humidity is highest within summer months. For intercept value $\delta_{0}$ which represent base demand, it is obtained highest in winter $\left(\mathrm{WDPD}_{11}\right)$, and lowest in spring $\left(\mathrm{SDPD}_{17}\right)$. Holidays $D H$ which represents peak demand reduction is the highest in summer.

For EPD models, they have $R^{2}$ values around $70.70 \%$ to $85.98 \%$ as in Table 6. Driver variables can explain EPD highest in autumn at 19:00 and on the contrary, the lowest in winter at 18:00. All variables in summer $\left(\mathrm{SMEPD}_{19}\right)$ and in spring $\left(\mathrm{SEPD}_{19}\right)$ have significance in models. Meanwhile $H D D$ and $R H D$ are found have no significance in autumn $\left(\mathrm{AEPD} \mathrm{D}_{19}\right)$ and in winter $\left(\mathrm{WEPD}_{18}\right)$, respectively. This confirmed that key drivers for EPD at studied demand place are not same in each season. In other words, certain variables 
affect peak demand only under specific season. Elimination of non-significance variable gives almost same regression results. $C D D$ and $H D D$ are the most significance meteorological variables. Under hot seasons, $C D D$ has highest significance for evening maximum loads. Meanwhile under

Table 1. Regression coefficients of seasonal ADT model with optimum $T_{\text {ref }}$

\begin{tabular}{|c|c|c|c|c|c|c|c|c|}
\hline \multirow{2}{*}{ Explanation Variable } & \multicolumn{2}{|c|}{$\begin{array}{c}\text { CECSM } \\
\left(\mathrm{T}_{\mathrm{ref}}=20^{\circ} \mathrm{C}\right) \\
\end{array}$} & \multicolumn{2}{|c|}{$\begin{array}{c}\text { CECA } \\
\left(T_{\text {ref }}=20^{\circ} \mathrm{C}\right)\end{array}$} & \multicolumn{2}{|c|}{$\begin{array}{c}\text { CECW } \\
\left(T_{\text {ref }}=16^{\circ} \mathrm{C}\right)\end{array}$} & \multicolumn{2}{|c|}{$\begin{array}{c}\text { CECS } \\
\left(T_{\text {ref }}=16^{\circ} \mathrm{C}\right) \\
\end{array}$} \\
\hline & Coef. & $\begin{array}{c}\text { Prob. } \\
(p-v a l u e)\end{array}$ & Coef. & $\begin{array}{c}\text { Prob. } \\
(p-v a l u e) \\
\end{array}$ & Coef. & $\begin{array}{c}\text { Prob. } \\
(p-\text { value }) \\
\end{array}$ & Coef. & $\begin{array}{c}\text { Prob. } \\
(p-v a l u e)\end{array}$ \\
\hline \multirow{2}{*}{$\beta_{0}$} & 1.6721 & 0 & 1.6866 & 0 & 2.0258 & 0 & 1.6176 & 0 \\
\hline & (27.90) & $0.0599 *$ & $(47.60)$ & $0.0354 *$ & \multirow[t]{3}{*}{$(59.15)$} & \multirow[t]{3}{*}{$0.0342 *$} & (49.82) & $0.0324 *$ \\
\hline \multirow{2}{*}{ CDD } & 0.0514 & 0 & 0.0577 & 0 & & & 0.0089 & 0 \\
\hline & (23.73) & $0.0021 *$ & (19.92) & $0.0029 *$ & & & $(7.20)$ & $0.0012 *$ \\
\hline \multirow{2}{*}{ HDD } & & & 0.0085 & 0 & 0.0164 & 0 & 0.0194 & 0 \\
\hline & & & $(7.85)$ & $0.0010^{*}$ & (14.42) & $0.0011 *$ & (19.58) & $0.0009 *$ \\
\hline \multirow{2}{*}{ RHD } & 0.0049 & 0 & 0.0013 & 0 & -0.0005 & 0.0026 & 0.0012 & 0 \\
\hline & (15.23) & $0.0003 *$ & (7.07) & $0.0001 *$ & $(-3.01)$ & $0.0001 *$ & (10.30) & $0.0001 *$ \\
\hline \multirow{2}{*}{$\mathrm{DH}$} & -0.2238 & 0 & -0.1528 & 0 & -0.1813 & 0 & -0.1306 & 0 \\
\hline & $(-33.88)$ & $0.0066^{*}$ & $(-32.20)$ & $0.0047 *$ & $(-29.61)$ & $0.0061 *$ & $(-30.25)$ & $0.0043 *$ \\
\hline
\end{tabular}

() t-statistic, *adjs. standard error.

Table 2. Regression statistics of ADT models

\begin{tabular}{|c|c|c|c|c|c|c|c|}
\hline Seasonal Model & $\mathbf{R}^{2}$ & $\mathbf{R}^{2}$ & D-W & SE Reg. & Prob. (F-Stat) & AIC & SC \\
\hline CECSM & 0.9011 & 0.9011 & 2.1567 & 0.2143 & 0.0000 & -0.2418 & -0.2357 \\
\hline CECA & 0.8960 & 0.8959 & 2.0860 & 0.1741 & 0.0000 & -0.6568 & -0.6495 \\
\hline CECW & 0.8133 & 0.8131 & 2.0838 & 0.1750 & 0.0000 & -0.6462 & -0.6374 \\
\hline CECS & 0.8602 & 0.8600 & 2.1167 & 0.1238 & 0.0000 & -1.3383 & -1.3282 \\
\hline
\end{tabular}

Table 3. Regression coefficients of daytime peak demand (DPD) model for related hour in each season

\begin{tabular}{|c|c|c|c|c|c|c|c|c|}
\hline \multirow{2}{*}{ Explanation Variable } & \multicolumn{2}{|c|}{ SMDPD $_{16}$} & \multicolumn{2}{|c|}{$\mathbf{A D P D}_{17}$} & \multicolumn{2}{|c|}{ WDPD $_{11}$} & \multicolumn{2}{|c|}{ SDPD $_{17}$} \\
\hline & Coef. & $\begin{array}{c}\text { Prob. } \\
(p-\text {-value })\end{array}$ & Coef. & $\begin{array}{c}\text { Prob. } \\
(p \text {-value })\end{array}$ & Coef. & $\begin{array}{c}\text { Prob. } \\
\text { (p-value })\end{array}$ & Coef. & $\begin{array}{c}\text { Prob. } \\
(p \text {-value })\end{array}$ \\
\hline \multirow{2}{*}{$\delta_{0}$} & 2.0653 & 0 & 1.9593 & 0 & 2.4007 & 0 & 1.7407 & 0 \\
\hline & $(8.36)$ & $0.2469 *$ & (23.37) & $0.0838 *$ & \multirow[t]{3}{*}{$(36.50)$} & \multirow[t]{3}{*}{$0.0657^{*}$} & $(42.92)$ & $0.0405^{*}$ \\
\hline \multirow{2}{*}{ CDD } & 0.0689 & 0 & 0.0798 & 0 & & & 0.0275 & 0 \\
\hline & $(6.80)$ & $0.0101 *$ & $(6.46)$ & $0.0123 *$ & & & $(5.37)$ & $0.0051 *$ \\
\hline \multirow{2}{*}{ HDD } & & & 0.0019 & $\underline{0.8076}$ & 0.0184 & 0.0007 & 0.0244 & 0.0001 \\
\hline & & & $(0.24)$ & $0.0080 *$ & $(3.46)$ & $0.0053 *$ & $(4.01)$ & $0.0060 *$ \\
\hline \multirow{2}{*}{ RHD } & 0.0072 & 0.0011 & 0.0041 & 0 & -0.0012 & $\underline{0.1097}$ & 0.0040 & 0 \\
\hline & $(3.30)$ & $0.0022 *$ & $(4.18)$ & $0.0009 *$ & $(-1.60)$ & $0.0007 *$ & (7.69) & $0.0005 *$ \\
\hline \multirow{2}{*}{$\mathrm{DH}$} & -0.4751 & 0 & -0.3154 & 0 & -0.3086 & 0 & -0.2731 & 0 \\
\hline & $(-18.05)$ & $0.0263^{*}$ & $(-13.22)$ & $0.0238^{*}$ & $(-11.57)$ & $0.0266^{*}$ & $(-17.52)$ & $0.0155^{*}$ \\
\hline
\end{tabular}

() t-statistic, *adjs. standard error, _ the related variable is not significant. 
Table 4. Regression statistics of DPD models

\begin{tabular}{cccccccc}
\hline DPD Model & $\mathbf{R}^{2}$ & $\mathbf{R}^{2}$ & D-W & SE Reg. & Prob. (F-Stat) & AIC & SC \\
\hline SMDPD $_{16}$ & 0.8668 & 0.8643 & 2.0889 & 0.1920 & 0.0000 & -0.4401 & -0.3610 \\
ADPD $_{17}$ & 0.8543 & 0.8509 & 2.0323 & 0.1953 & 0.0000 & -0.4029 & -0.3099 \\
WDPD $_{11}$ & 0.6812 & 0.6720 & 1.9986 & 0.1627 & 0.0000 & -0.7598 & -0.6530 \\
SDPD $_{17}$ & 0.7539 & 0.7455 & 1.9733 & 0.1062 & 0.0000 & -1.6077 & -1.4845 \\
\hline
\end{tabular}

$\mathrm{R}^{2}$ without $\mathrm{HDD}$ in $\mathrm{ADPD}_{17}$ model is $85.15 \%, \mathrm{R}^{2}$ without $\mathrm{RHD}$ in $\mathrm{WDPD}_{11}$ is $66.96 \%$.

Table 5. Regression coefficients for seasonal evening peak demand (EPD) model

\begin{tabular}{|c|c|c|c|c|c|c|c|c|}
\hline \multirow{2}{*}{ Explanation Variable } & \multicolumn{2}{|c|}{ SMEPD $_{19}$} & \multicolumn{2}{|c|}{$\mathbf{A E P D}_{19}$} & \multicolumn{2}{|c|}{ WEPD $_{18}$} & \multicolumn{2}{|c|}{ SEPD $_{19}$} \\
\hline & Coef. & $\begin{array}{c}\text { Prob. } \\
\text { (p-value })\end{array}$ & Coef. & $\begin{array}{c}\text { Prob. } \\
(p-\text {-value })\end{array}$ & Coef. & $\begin{array}{c}\text { Prob. } \\
\text { (p-value })\end{array}$ & Coef. & $\begin{array}{c}\text { Prob. } \\
\text { (p-value) }\end{array}$ \\
\hline \multirow{2}{*}{$\gamma_{0}$} & 1.8988 & 0 & 2.1049 & 0 & 2.3699 & 0 & 1.8617 & 0 \\
\hline & $(9.75)$ & $0.1946^{*}$ & $(23.44)$ & $0.0897^{*}$ & \multirow[t]{3}{*}{$(39.01)$} & \multirow[t]{3}{*}{$0.0607^{*}$} & $(40.47)$ & $0.0459^{*}$ \\
\hline \multirow{2}{*}{ CDD } & 0.0680 & 0 & 0.0648 & 0 & & & 0.0272 & 0 \\
\hline & $(7.31)$ & $0.0093^{*}$ & $(5.52)$ & $0.0117^{*}$ & & & $(6.73)$ & $0.0040^{*}$ \\
\hline \multirow{2}{*}{ HDD } & & & -0.0018 & $\underline{0.7722}$ & 0.0289 & 0 & 0.0283 & 0 \\
\hline & & & $(-0.28)$ & $0.0064 *$ & $(5.96)$ & $0.0048^{*}$ & $(5.25)$ & $0.0054^{*}$ \\
\hline \multirow{2}{*}{ RHD } & 0.0082 & 0 & 0.0028 & 0.0026 & 0.0007 & $\underline{0.3402}$ & 0.0029 & 0 \\
\hline & $(4.39)$ & $0.0018^{*}$ & $(3.04)$ & $0.0009^{*}$ & $(0.95)$ & $0.0007^{*}$ & $(6.76)$ & $0.0004 *$ \\
\hline \multirow{2}{*}{ DH } & -0.2995 & 0 & -0.2005 & 0 & -0.3178 & 0 & -0.1983 & 0 \\
\hline & $(-12.52)$ & $0.0239^{*}$ & $(-10.79)$ & $0.0185^{*}$ & $(-12.66)$ & 0.0251 & $(-17.59)$ & $0.0112 *$ \\
\hline
\end{tabular}

() t-statistic, *adjs. standard error,_the related variable is not significant.

Table 6. Regression statistics of EPD models

\begin{tabular}{|c|c|c|c|c|c|c|c|}
\hline EPD Model & $\mathbf{R}^{2}$ & $\mathbf{R}^{2}$ & D-W & SE Reg. & Prob. (F-Stat) & AIC & SC \\
\hline SMEPD $_{19}$ & 0.8200 & 0.8166 & 2.1233 & 0.1907 & 0.0000 & -0.4539 & -0.3748 \\
\hline $\mathrm{AEPD}_{19}$ & 0.8629 & 0.8598 & 1.9537 & 0.1603 & 0.0000 & -0.7975 & -0.7045 \\
\hline $\mathrm{WEPD}_{18}$ & 0.7152 & 0.7070 & 1.9870 & 0.1463 & 0.0000 & -0.9724 & -0.8655 \\
\hline $\mathrm{SEPD}_{19}$ & 0.8139 & 0.8075 & 1.9587 & 0.0850 & 0.0000 & -2.0531 & -1.9299 \\
\hline
\end{tabular}

$\mathrm{R}^{2}$ without HDD in $\mathrm{AEPD}_{19}$ model is $86.03 \%, \mathrm{R}^{2}$ without $\mathrm{RHD}$ in $\mathrm{WEPD}_{18}$ is $70.73 \%$.

cold seasons is $H D D$. However, the highest coefficient of $C D D$ and $H D D$ are obtained in summer model at 19:00 $(0.0680)$ and winter model at 18:00 (0.0289), respectively. For base demand, it is highest in winter $\left(\mathrm{WEPD}_{18}\right)$, and lowest in spring $\left(\mathrm{SEPD}_{19}\right)$ as shown by $\gamma_{0}$ values. Holidays $\mathrm{DH}$ reduces demand highest in winter at 18:00.

\subsection{Characteristics Comparison between Peak Demand and All-Demand-Time for Each Season}

For further analysis, characteristics for peak demands (DPD and EPD) and all-demand-time (ADT) are compared. The $R^{2}$ values are larger for $A D T$ models than peaks models.
Next, it is found that intercept values of $\beta_{0}$ is smaller than $\delta_{0}$ and $\gamma_{0}$ for all models. This indicates base load during $D P D$ and $E P D$ is larger than in $A D T$ in all seasons. As in $D P D$ time, electric equipments which possibly donate to base demand are used following high business activity, and utilization or additional lighting in evening ( $E P D$ time) may give contribution.

Concerning meteorological variables (CDD, HDD, and RHD), related coefficients are larger for peak demand models than for $A D T$ models, excluding $H D D$ for both peak demands in autumn $\left(\mathrm{ADPD}_{17}\right.$ and $\left.\mathrm{AEPD}_{19}\right)$ and $R H D$ in winter $\left(\mathrm{WDPD}_{11}\right.$ and $\left.\mathrm{WEPD}_{18}\right)$ which have no significance 
in the models. For significance variables, it confirms demands are influenced much by related meteorological conditions at peak hours rather than in all-demand-time generally. More utilization of cooling or heating equipments during peak hours in the related season is needed at business places. Next, regarding holidays, it will reduce more demand at peak hours than at $A D T$.

\section{Conclusions}

This paper provides seasonal peak demand characteristics analysis for Japanese commercial area by using regression model. Meteorological parameters and holidays are used as explanation variables. Investigation involves daytime and evening peak demand (DPD and EPD). Next, demand models for related peak hours in each season are composed based on the best seasonal (ADT) models. Peaks for summer, autumn, and spring occur almost at the same hour. Meanwhile for winter is slightly different (occurred earlier), and mainly for daytime peak. It indicates peak hours may change by season. The peak demands tend to higher under hot seasons (summer and autumn) than in cold seasons (winter and spring). Under hot seasons, $D P D$ are relatively higher than $E P D$ and in contrast in the cold seasons.

From results, more specific characteristics for peak demands can be revealed. Hourly demand models are validated well. Adjusted coefficient of determination $R^{2}$ values are around $67.20 \%$ to $86.43 \%$ for $D P D$ models, and around $70.70 \%$ to $85.98 \%$ for $E P D$ models which designates the models have fairly good fitness degree. Variables can explain peak demand optimally in the evening than in daytime excluding in summer. At peak hours, all variables have significance for summer and spring. Meanwhile $H D D$ variable is not significant in autumn, and likewise $R H D$ in winter. It reflects key drivers for peaks are not same in each season. $C D D$ and $H D D$ have highest effect on peak demands among meteorological variables. For base demand, it tends to high in winter and on the contrary in spring. Holidays $D H$ will make peak demand lower in all seasons but in difference quantity. Additionally, comparison results show characteristics at peak hours are unique. When $A D T$ model used as a reference value, the influence magnitude of the significance variables on peak demands tends to larger in each season generally.

The presented information may help utilities in identifying typical link of peak loads to their drivers more detail, and in decision making for operation planning in power systems especially during high demand hours in different seasons.

\section{References}

[1] S. B. Sadineni, and R. F. Boehm, "Measurements and Simulations for Peak Electrical Load Reduction in Cooling Dominated Climate,” Energy, Vol. 37, pp. 689-697, 2012.

[2] F. Egelioglu, A. A. Mohamad, and H. Guven, "Economic Variables and Electricity Consumption in Northern Cyprus," Energy, Vol. 26, pp. 355-362, 2001.

[3] A. Pardo, V. Meneu and E. Valor, "Temperature and Seasonality Influences on Spanish Electricity Load," Energy Economics, Vol. 24, pp. 55-70, 2002.

[4] K. Wangpattarapong, S. Maneewan, N. Ketjoy and W. Rakwichian, "The Impacts of Climatic and Economic Factors on Residential Electricity Consumption of Bangkok Metropolis," Energy and Buildings, Vol. 40, pp. 1419-1425, 2008.

[5] M. A. Momani, "Factors Affecting Electricity Demand in Jordan," Energy and Power Engineering, Vol. 5, No. 1, pp. 50-58, 2013.

[6] S. Mirasgedis, Y. Sarafidis, E. Georgopoulou, D. P. Lalas, M. Moschovits, F. Karagiannis and D. Papakonstantinou, "Models for Mid-Term Electricity Demand Forecasting Incorporating Weather Influences," Energy, Vol. 31, pp. 208-227, 2006.

[7] D. H. W. Li, J. C. Lam, and S. L. Wong, "Daylighting and Its Effects on Peak Load Determination," Energy, Vol. 30, pp. 1817-1831, 2005.

[8] M. A. Almeida, R. Schaeffer, and E. L. La Rovere, "The Potential for Electricity Conservation and Peak Load Reduction in the Residential Sector of Brazil," Energy, Vol. 26, pp. 413-429, 2001.

[9] S. Dudhani, A. K. Sinha, and S. S. Inamdar, "Renewable Energy Sources for Peak Load Demand Management in India," Electrical Power and Energy Systems, Vol. 28, pp. 396-400, 2006.

[10] Y. S. Akil, and H. Miyauchi, "Seasonal Regression Models for Electricity Consumption Characteristics Analysis," Engineering, Vol. 5, No. 1B, pp. 108-114, 2013.

[11] Japan Meteorological Agency (JMA).http://www.jma.go.jp/jma/indexe.html

[12] B. E. Psiloglou, C. Giannakopoulos, S. Majithia, and M. Petrakis, "Factors Affecting Electricity Demand in Athens, Greece and London, UK: A Comparative Assessment," Energy, Vol. 34, pp. 1855-1863, 2009.

[13] R. Startz, EViews Illustrated for Version 6, 1st Ed., Quantitative Micro Software, LLC, 2007.

[14] EViews. http://www.eviews.com 